\title{
Demographic and cardiovascular risk factors associated with drug use in truck drivers in the state of São Paulo: A cross-sectional study.
}

\section{Mariana Moura Pereira}

Universidade de Sao Paulo Faculdade de Medicina

Antonio Padua Mansur ( $\sim$ apmansur@yahoo.com )

Universidade de São Paulo Faculdade de Medicina Hospital das Clínicas Instituto do Coração https://orcid.org/0000-0003-3051-1090

\section{Julio Yoshio Takada}

Universidade de Sao Paulo Faculdade de Medicina

\section{Vilma Leyton}

Universidade de Sao Paulo Faculdade de Medicina

Research article

Keywords: truck drivers, illicit drugs, risk factors, smoking, alcohol consumption.

Posted Date: August 19th, 2020

DOI: https://doi.org/10.21203/rs.3.rs-21248/v2

License: (c) (i) This work is licensed under a Creative Commons Attribution 4.0 International License. Read Full License 


\section{Abstract}

Background: The irregular routine of truck drivers favors the development of chronic noncommunicable diseases (NCDs), especially cardiovascular diseases (CVDs), which can be exacerbated by the use of illicit drugs.

Methods: A cross-sectional study was carried out with data from 2,071 truck drivers who traveled through the state of São Paulo between 2010 and 2016. Socioeconomic and occupational variables, risk factors for CVD, use of illicit drugs were analyzed. Clinical and toxicological tests were also carried out.

Results: The average age of the truck drivers was $42.27 \pm 11.07$ years, and the use of illicit drugs, at least once while working, was reported or detected in 388 (18.7\%) drivers. Compared to non-users, drug users were younger ( $37.25 \pm 9.45$ vs. $43.43 \pm 11.1$ years; $p<0.001)$ and single $(43.3 \%$ vs. $28.4 \% ; p<0.001)$. The independent variables age [OR $=0.93$ (95\% Cl: $0.91-0.95 ; p<0.001)$ ], smoking [OR $=2.18$ (95\% Cl: 1.39 3.44; $p=0.001)$ ], alcohol consumption [OR = $1.626(95 \% \mathrm{Cl}: 1.06-2.49 ; \mathrm{p}=0.026)]$ and hours of driving per day $[\mathrm{OR}=1.08(95 \% \mathrm{Cl}: 1.01-1.15 ; \mathrm{p}=0.012)$ ] were also associated with the use of illicit drugs.

Conclusion: The use of illicit drugs was higher in young and single drivers and was associated with a higher prevalence of smoking, alcohol consumption and more driving hours, which are risk factors for NCDs, CVD and traffic accidents.

\section{Background}

Approximately $61 \%$ of cargo transportation in Brazil is performed by the road sector, which also plays a large role in the production of wealth, having reached $36.2 \%$ of the GDP in $2014 .{ }^{1}$ Additionally, cargo transportation is one of the sectors that generates more jobs, with an estimated 472.2 thousand workers in 2015. In Brazil, 8,227 fatal traffic accidents were recorded, and another 100,000 resulted in serious injuries to drivers in 2014. In the 71 thousand kilometers of the federal highway network, accidents involving trucks accounted for a proportionally higher percentage of fatal accidents and those resulting in serious injuries. ${ }^{2}$ The work pattern of truck drivers is a topic of great relevance in the world economy and public health setting. Physical and mental health are two essential aspects for the safe driving of heavy vehicles without putting lives at risk ${ }^{3-5}$. Professional drivers are often exposed to overtime work, irregular sleep patterns and short delivery times. After many years being a professional driver, these factors contribute strongly to a higher incidence of chronic non-communicable diseases (NCDs) and the occurrence of traffic accidents. ${ }^{3}$

A recent study showed an association between patients with metabolic syndrome and sleepiness, which resulted in an increase in traffic accidents. ${ }^{4}$ Inadequate nutrition and lack of physical activity among truck drivers are the main factors for the development of metabolic syndrome. In addition, poor eating habits, obesity and irregular sleep patterns lead to obstructive sleep apnea and, consequently, excessive daytime sleepiness, which is also an important risk factor for accidents. In truck drivers, lifestyle was 
associated with a higher incidence of heart disease, obesity, sleep disorders and diabetes, and these diseases increase the risk of road accidents. ${ }^{5}$ In addition, the use of psychoactive substances has also been used by drivers to alleviate the fatigue resulting from long distance trips, driving at night, having short rest periods and few hours of sleep. The precarious working conditions and the need to combat tiredness were the main justifications for the use of these drugs impacting even more on traffic accidents. ${ }^{6-12}$ Regarding the relationship between health risk factors and drug use, a study conducted with young people between 15 and 35 years old showed that illicit drugs have an important effect on sudden cardiac death. ${ }^{13}$ Considered cardiotoxic substances, illicit drugs, mainly cocaine, amphetamine and marijuana, were detected in 29 young drivers among the 98 analyzed. Substances toxic to the heart have also been found to be present, mainly in individuals who died from chronic or acute ischemic heart disease. ${ }^{13}$ There are also reports that cocaine use and abuse are associated with an increased risk of cardiovascular complications, such as systemic arterial hypertension (SAH), coronary artery spasm, arrhythmias, acute myocardial infarction (MI), cardiomyopathy and atherosclerotic coronary artery disease. ${ }^{14}$

In turn, tetrahydrocannabinol (THC), the main active component of marijuana, causes an acute dosedependent increase in blood pressure (BP) and heart rate. A review explored a series of studies on the topic, and there was evidence to suggest that increasing the frequency of marijuana use increases the risk of cardiac arrhythmias and MI. ${ }^{15}$ The marijuana contaminants, such as acetaldehyde, ammonia, benzene, can also play a role in the development of life-threatening cardiovascular diseases. ${ }^{15}$ Tobacco

use also occurs frequently among marijuana users. ${ }^{15-18}$ Acute stroke has also been associated with marijuana use, cocaine and amphetamine. ${ }^{17}$ Marijuana use by young adults was associated with a $17 \%$ increase in stroke risk. ${ }^{18}$

The precarious working conditions and the use of illicit drugs were associated with NCDs and with traffic accidents. Nevertheless, little is known about demographic, occupational and risk factors for NCD data in truck drivers that use illicit drugs. The aim of this study was to analyze the relationship between the previous use of illicit drugs by truck drivers and health risk factors among these workers.

\section{Methods}

\section{Study participants}

This is a cross-sectional cohort study that analyzed 2071 truck drivers who traveled on highways in the State of São Paulo from 2010 to 2016. Drivers were randomly stopped to participate in the "Health Commands on the Roads" program promoted by the Federal Highway Police, which aims to promote the health of truck drivers on federal highways ${ }^{19}$. The purpose of the program is to provide guidance to professional drivers regarding good health habits for the prevention of diseases and traffic accidents, as well as to perform medical examinations to detect risk factors for chronic diseases. The participation of the drivers was voluntary, and participants were included in the study after signing a free and informed 
consent form. The exclusion criterion was distances smaller than $100 \mathrm{Km}$, small utility-service truck vehicle, individuals with questionnaires lacking essential data for analysis and not signing the informed consent form. The study was approved by the Research Ethics Committee of the School of Medicine, University of Sao Paulo (Protocol No. 2,022,550/2017).

\section{Data collection}

Drivers were asked about demographic data (age, sex, marital status, education level and socioeconomic level), occupational data (type of job, time in the profession, number of hours worked per day, type of journey and sleepiness), risk factors for NCDs (smoking, dyslipidemia, diabetes, high blood pressure, obesity and sleepiness) and the use of illicit drugs (crack, cocaine, marijuana, synthetic psychoactive drugs and amphetamine). Lifestyle was assessed in a qualitative way and considered sedentary according to the report of the absence of any additional physical activity unrelated to the regular workday. The Epworth Sleepiness Scale was used to assess sleepiness, with a cutoff of $\leq 10$ for nondrowsiness and $>10$ for sleepiness. ${ }^{20}$ Obesity was defined according to body mass index [BMI = weight $(\mathrm{kg}) /$ height $\left(\mathrm{m}^{2}\right)$ ] as follows: normal weight (BMI $\geq 18.5$ and $\left.<25\right)$, overweight (BMI $\geq 25$ and $<30$ ) and obesity $(\mathrm{BMI} \geq 30) .{ }^{21} \mathrm{SAH}$ was diagnosed according to values of systolic blood pressure $>140 \mathrm{mmHg}$ and diastolic blood pressure $>90 \mathrm{mmHg}$ or if the participant used antihypertensive drugs. ${ }^{22}$ Dyslipidemia was diagnosed in individuals with total cholesterol $\geq 240 \mathrm{mg} / \mathrm{dL}$, triglycerides $\geq 150 \mathrm{mg} / \mathrm{dL}$, LDLcholesterol $(\mathrm{LDL}) \geq 130 \mathrm{mg} / \mathrm{dL}$, or statin use. ${ }^{23}$ Diabetes was diagnosed in individuals with fasting glucose $\geq 126 \mathrm{mg} / \mathrm{dL}$ or casual blood glucose $\geq 200 \mathrm{mg} / \mathrm{dL}$ or if hypoglycemic agents were used. ${ }^{24}$ The percentage of body fat was calculated using the formula: \% body fat $=495 /(1.0324-0.19077$ (log (waistneck $))+0.15456(\log ($ height $)))-450(\log 10) .{ }^{25}$ The circumferences of the neck and waist were considered above the normal limit if the values were $\geq 40 \mathrm{~cm}$ and $\geq 109 \mathrm{~cm}$, respectively. ${ }^{26}$ Alcohol consumption, involvement in traffic accidents and the transport of dangerous cargo were assessed via direct questions with a positive or negative answer. The distance traveled took into account the city of departure and the city of the destination and was defined in $\mathrm{km}$ in the driver's report.

\section{Toxicological Analysis}

Urine and oral fluid were also collected from the drivers for toxicological testing. Quick tests were applied at the site to measure blood glucose, cholesterol and triglyceride levels. Samples for toxicological analysis were collected in the field and analyzed in the laboratory. The following drugs and/or their metabolites were researched: cocaine, cannabis and amphetamine. Immunoassay screening tests were carried out, and the positive results were confirmed by mass spectrometry using previously described methodologies. $^{9,11}$

\section{Statistical analysis}

Drivers were divided into two groups: those who reported never having used illicit drugs and those who reported having used illicit drugs at least once in their lives. For continuous variables, the analysis was 
performed by observing the minimum and maximum values and calculating means and standard deviations. For categorical variables, absolute and relative frequencies were calculated. Student's t test was used for independent samples when comparing a normally distributed quantitative variable between two groups. The normal distribution for Student's t test was verified by the method of analysis of equality of variances (Folded F). Depending on the results of this analysis, the pooled method (variances with $p \geq$ 0.05 ) or the Satterthwaite method (variances with $p<0.05$ ) were used. The chi-square test was used for categorical variables. The stepwise logistic regression model was used for multivariate analysis. The dependent variable was determined as the use or not of the drugs studied, and the independent variables selected in the model were those with $p<0.1$ at bivariate analysis. The independent variables included in the model were marital status, education, previous traffic accidents, diabetes, high blood pressure, smoking, alcohol consumption, physical activity, hours of sleep, age, time in the profession, hours of driving, Epworth sleepiness questionnaire with values categorized as $\leq 10$ and $>10$ points, blood glucose (categorized as $\leq 100$ and $>100 \mathrm{mg} / \mathrm{dL}$ ), triglyceride levels (categorized as $\leq 150$ and $>150 \mathrm{mg} / \mathrm{dL}$ ), total cholesterol (categorized as $\leq 200$ and $>200 \mathrm{mg} / \mathrm{dL}$ ), BMI (categorized as $<25$ and $\geq 25 \mathrm{Kg} / \mathrm{m}^{2}$ ) and age. The significance level adopted for the statistical tests was $5 \%(p<0.05)$. Statistical analyses were performed using the program SAS, University Edition ${ }^{\circledR}$ (SAS Institute Inc., NC, USA).

\section{Results}

The demographic, occupational, clinical, laboratory data and use of illicit drugs of 2017 truck drivers who traveled on highways in the State of São Paulo from 2010 to 2016 are shown in Table 1. The mean age was $42.3 \pm 11.1$ years. They were mostly non-single (68.8\%), with a predominant level of education up to 8 years of study (49.9\%), corresponding to elementary school. They have an average professional experience of $15.8 \pm 11.3$ years, $66.1 \%$ were hired by companies, $18.9 \%$ had at least one traffic accident and $13.2 \%$ carried dangerous cargo. The total of 388 drivers who reported the use of illicit drugs at least once in their lives were mostly single and younger, with a higher level of education, less experience in the driving profession, a lower percentage of body fat, a lower prevalence of hypertension and greater use of alcohol and tobacco. The most prevalent drugs were marijuana (42\%), amphetamine (39\%) and cocaine (17\%). In 52 (32\%) drivers who declare marijuana users, 43 (26\%) also declared concomitant use of cocaine, and $9(6 \%)$ used crack in addition to marijuana and cocaine. Among the 72 drivers who declared themselves current users (18.7\%), the most prevalent drugs were marijuana (5.95\%), amphetamine (4.7\%) and cocaine (4.5\%), which also appeared as combinations: cocaine and marijuana (2.2\%), amphetamine and cocaine $(0.4 \%)$, amphetamine and marijuana $(0.3 \%)$ and amphetamine, cocaine and marijuana (0.2\%).

Table 1. Sociodemographic and clinical data collected from 2071 truck drivers who traveled through the state of São Paulo between 2010 and 2016, classified according to the self-report of consumption of illicit drugs. 


\begin{tabular}{|c|c|c|c|c|}
\hline \multicolumn{5}{|c|}{ Illicit drugs } \\
\hline Variable & Total $(n=2071)$ & Used at least once $(n=388)$ & $\begin{array}{l}\text { Never used } \\
(\mathrm{n}=1683)\end{array}$ & $|\mathrm{p}|$ \\
\hline Age (years) & $42.27 \pm 11.07$ & $37.25 \pm 9.45$ & $43.43 \pm 11.09$ & $<.0001$ \\
\hline Marital status (\%) & & & & \\
\hline Single & $645(31.2)$ & $168(43.3)$ & $477(28.4)$ & \\
\hline Not single & 1423 (68.8) & $220(56.70)$ & 1203 (71.6) & $<.0001$ \\
\hline Education level (\%) & & & & \\
\hline Up to 8 years & $1,032(49.9)$ & $152(39.2)$ & $880(52.35)$ & \\
\hline From 9 to 11 years & $976(47.2)$ & $220(56.7)$ & $756(45)$ & \\
\hline Over 11 years & $61(2.9)$ & $16(4.1)$ & $45(2.65)$ & $<.0001$ \\
\hline Type of contract (\%) & & & & \\
\hline Self-employed & $688(33.3)$ & $128(33.1)$ & $560(33.35)$ & \\
\hline Hired & $1,366(66.1)$ & $258(66.7)$ & $1,108(66)$ & \\
\hline Other & $12(0.6)$ & $1(0.2)$ & $11(0.65)$ & 0.817 \\
\hline Traffic accidents (\%) & $391(18.9)$ & $90(23.2)$ & $301(17.9)$ & 0.016 \\
\hline Dangerous cargo (\%) & $272(13.2)$ & $55(14.2)$ & $217(12.9)$ & 0.499 \\
\hline Sleeping hours (hours) & $7.57 \pm 1.54$ & $7.4 \pm 1.68$ & $7.61 \pm 1.51$ & 0.027 \\
\hline Profession duration (years) & $15.85 \pm 11.3$ & $12.36 \pm 9.18$ & $16.65 \pm 11.59$ & $<.0001$ \\
\hline Driving hours per day (hours) & $9.07 \pm 3.19$ & $9.79 \pm 3.33$ & $8.91 \pm 3.13$ & $<.0001$ \\
\hline Distance travelled (km) & $633.96 \pm 850.03$ & $798.19 \pm 841.26$ & $596.1 \pm 847.79$ & $<.0001$ \\
\hline Smoking (\%) & $474(22.9)$ & $129(33.3)$ & $345(20.5)$ & $<.0001$ \\
\hline Alcohol consumption (\%) & $969(47.1)$ & $207(53.8)$ & $762(45.6)$ & 0.003 \\
\hline Hypertension (\%) & $294(14.2)$ & $38(9.8)$ & $256(15.2)$ & 0.005 \\
\hline Diabetes (\%) & $131(6.3)$ & $17(4.4)$ & $114(6.8)$ & 0.080 \\
\hline Body mass index $(\mathrm{kg} / \mathrm{m} \rrbracket)$ & $28.32 \pm 5.01$ & $28.28 \pm 4.88$ & $28.46 \pm 5.52$ & 0.310 \\
\hline Waist circumference $(\mathrm{cm})$ & $99.09 \pm 13.14$ & $99.11 \pm 12.88$ & $99.01 \pm 14.24$ & 0.898 \\
\hline Neck circumference $(\mathrm{cm})$ & $40.89 \pm 4.23$ & $40.84 \pm 4.10$ & $41.11 \pm 4.75$ & 0.291 \\
\hline Body fat (\%) & $24.32 \pm 7.87$ & $23.51 \pm 8.17$ & $24.5 \pm 7.79$ & 0.356 \\
\hline Glucose (mg/dL) & $100.27 \pm 42.96$ & $97.67 \pm 44.03$ & $100.87 \pm 42.70$ & 0.199 \\
\hline Triglycerides (mg/dL) & $199.74 \pm 111.10$ & $185.81 \pm 102.60$ & $202.53 \pm 112.57$ & 0.096 \\
\hline Cholesterol (mg/dL) & $193.5 \pm 33.35$ & $190.02 \pm 32.68$ & $194.17 \pm 33.46$ & 0.172 \\
\hline
\end{tabular}

Logistic regression of unadjusted and adjusted odds ratio estimates are shown in Table 2. Multivariable logistic regression analysis using illicit drugs as a dependent variable, we identified age [OR $=0.93(95 \%$ Cl: 0.91 - 0.95; $p<0.001)$ ], smoking [OR = 2.18 (95\% Cl: 1.39 - 3.44; $p=0.001)$ ], alcohol consumption [OR = 1.626 (95\% Cl: 1.06 - 2.49; $p=0.026)$ ] and daily driving time [OR = 1, 08 (95\% Cl: 1.01 - 1.15; $p=0.012)]$ as independent variables for illicit drugs (figure 1).

Table 2. Logistic regression analysis of unadjusted and adjusted odds ratio and $95 \%$ Wald confidence limits of the data collected from 2071 truck drivers, classified according to the self-report of consumption of illicit drugs. 


\begin{tabular}{|c|c|c|c|c|c|c|}
\hline \multirow[t]{3}{*}{ Variables } & \multicolumn{6}{|c|}{ Odds Ratio Estimates } \\
\hline & \multicolumn{3}{|c|}{ Unajusted } & \multicolumn{3}{|c|}{ Adjusted } \\
\hline & Point Estimate & (95\%) Wald CL & $|\mathrm{p}|$ & Point Estimate & (95\%) Wald CL & $|\mathrm{p}|$ \\
\hline Age (years) & 0.93 & $0.91-0.95$ & $<0.001$ & 0.94 & 0.93-0.95 & $\mathrm{p}<0.001$ \\
\hline Marital Status & 0.71 & $0.59-0.85$ & 0.001 & 0.76 & $0.48-1.22$ & 0.257 \\
\hline Education level & 1.59 & $1.31-1.94$ & $<0.001$ & 1.12 & $0.75-1.67$ & 0.588 \\
\hline Traffic acidentes & 1.39 & $1.06-1.81$ & 0.016 & 1.54 & $0.88-2.74$ & 0.140 \\
\hline Sleeping hours & 0.92 & $0.85-0.98$ & 0.017 & 1.00 & $0.87-1.14$ & 0.961 \\
\hline Profession duration & 0.96 & $0.95-0.97$ & $<0.001$ & 1.00 & $0.96-1.04$ & 0.987 \\
\hline Driving hours/day & 1.09 & $1.05-1.13$ & $<0.001$ & 1.08 & $1.01-1.15$ & 0.012 \\
\hline Smoking & 1.94 & $1.52-2.47$ & $<0.001$ & 2.18 & $1.39-3.44$ & 0.001 \\
\hline Alcohol consumption & 1.39 & $1.11-1.73$ & 0.004 & 1.63 & $1.06-2.49$ & 0.026 \\
\hline Hypertension & 0.61 & $0.42-0.87$ & 0.006 & 0.94 & $0.44-1.99$ & 0.864 \\
\hline Diabetes & 0.63 & $0.37-1.06$ & 0.083 & 1.17 & $0.33-4.15$ & 0.802 \\
\hline Body mass index & 0.92 & $0.72-1.18$ & 0.520 & 1.02 & $0.97-1.06$ & 0.467 \\
\hline Glucose & 0.72 & $0.49-1.06$ & 0.096 & 1.00 & $0.99-1.01$ & 0.860 \\
\hline Tryglicerides & 0.67 & $0.47-0.96$ & 0.030 & 0.66 & $0.41-1.05$ & 0.467 \\
\hline Cholesterol & 0.59 & $0.39-0.87$ & 0.008 & 0.70 & $0.43-1.15$ & 0.206 \\
\hline
\end{tabular}

\section{Discussion}

This study showed that the consumption of illicit drugs was higher in young drivers, smokers, and those who frequently consumed alcohol and who had a higher average number of daily driving hours. The prevalence of the use of illicit drugs and alcohol consumption found in the present study is within the average found in the literature for studies based on reports by truck drivers. ${ }^{9}$ The percentages of consumption of amphetamine, marijuana and cocaine vary from $0.9 \%$ to $70 \%, 0.2$ to $29.9 \%$ and $0.1 \%$ to $8.3 \%$, respectively. This great variation between study results is probably due to methodological differences, sample variations and different geographic regions in which the research was carried out.

Amphetamine, known as "rebite" among Brazilian drivers, is used mainly as a stimulant to combat tiredness ${ }^{10}$, as its main effects are increased alertness, decreased fatigue, elevated mood, euphoria and increased motor activity ${ }^{27-29}$. In Brazil, due to side effects, the potential to cause addiction and the tendency toward indiscriminate use,

the sale, production and prescription of the substance has become prohibited in accordance with resolution RDC 52/2011 ${ }^{30,31}$. However, amid controversies among doctors and health agents, in 2017, a bill was approved for them to be produced, marketed and consumed under prescription again ${ }^{32}$.

Leyton and colleagues point out that the legislation may have caused a change in consumption patterns of amphetamine stimulants during the years in which it was in effect. ${ }^{33}$ Between 2009 and 2016, the analysis of 4,110 biological samples from drivers also showed an increase, although not statistically significant, in cocaine consumption. Amphetamine use changed over the years, with high consumption in 2010 (8.9\%) but a decline in 2011 and 2012 (1.7\% to 2.0\%), followed by a stable period from 2013 to 
2015 (ranging from $2.9 \%$ to $4.1 \%$ ). In this research, it was found that such drugs were mainly used to combat fatigue in long-distance drivers, but the possibility of recreational use in drivers working shorter hours is not ruled out.

During the period of this study (2010 to 2016), although the medication was prohibited, $33.33 \%$ of the drivers who declared consumption of other illicit drugs also reported the use of amphetamine as a stimulant. The amount is significantly higher than the $16.38 \%$ who reported having used amphetamine stimulants but did not report the use of other illicit drugs. Amphetamines exert peripheral sympathomimetic actions, producing elevated blood pressure, death of cardiac muscle cells, coronary insufficiency, increased heart rate and other cardiovascular changes resulting from increased concentration of norepinephrine in synapses ${ }^{34}$.

Cocaine acts on the nervous system by inhibiting the reuptake of norepinephrine, dopamine and serotonin through interaction with its transporters, resulting in prolongation and overactivity of the sympathetic nervous system. Another possible effect is the blocking of sodium/potassium channels, causing cardiovascular changes, which may present increased and prolonged risks when there is an association between cocaine and alcohol. ${ }^{17}$ In a review including a range of studies on the effects of the drug, it was found that its frequent use may be strongly associated with an increased risk of acute cardiovascular complications, such as hypertension, coronary aneurysms, arrhythmias and myocardial infarction ${ }^{16-18}$.

Cocaine and its metabolites also affect behavior regarding food intake and suppress appetite, which can lead to the disruption of metabolic and neuroendocrine regulation, resulting in an increased risk of developing body weight problems, diabetes and metabolic syndrome ${ }^{17}$. Studies with humans have also shown anorexigenic effects of cocaine, and the low caloric intake, together with abnormal metabolic and gastrointestinal functions, can lead to malnutrition among drug users ${ }^{17}$.

In this study, body fat and hypertension were significantly related to the reported consumption of illicit drugs, and the lower percentage of fat for users of illicit drugs is consistent with what was found in the literature, since amphetamine and cocaine have proven effects on metabolic functions and are anorectic agents $17,30,34$. Although the prevalence of hypertension found among those who declared they had already used illicit drugs (9.8\%) was lower than that found among those who had never used illicit drugs (15.2\%), it should be considered that this factor may also be directly linked to a low percentage of body fat and the young average age.

According to the Brazilian cardiovascular prevention guidelines (BCPG) 38, SAH is one of the most important risk factors for the development of coronary artery disease, heart failure, cerebral vascular disease, chronic kidney disease and atrial fibrillation. ${ }^{35}$ The BGPC also show that 22 studies found a prevalence of SAH in the adult population of between $22.3 \%$ and $43.9 \%$ (average of $32.5 \%$ ), being higher than the $50 \%$ prevalence identified in individuals between 60 and 69 years old and $75 \%$ in those over 70 
years old; that is, there is a lower occurrence in younger individuals, and there is a visible progressive increase according to age.

Although there is evidence of an association between marijuana use and acute cardiovascular problems, it was not possible to assess the long-term chronic effects of using this drug ${ }^{18}$. The first study to link ischemic stroke in humans with marijuana use was done in the United States, and even after adjusting for other substances of abuse and eliminating confounding variables, it was found that the association persisted, showing that it is independent of other factors ${ }^{17}$.

There is evidence that marijuana users who are also smokers are more likely to develop ischemic heart disease, a fact that was also reproduced by Singh and colleagues in a study review ${ }^{36}$. In view of the increase in drug use and the alarming number of new cardiovascular events related to it in recent decades, it is important to emphasize that there is a need to increase scientific work on this relation that is underestimated and underreported ${ }^{36}$.

The variable "illicit drugs", which had a positive association with the independent variables "age", "smoking", "alcohol consumption" and "marital status", provided us with a profile of consumption that showed that younger drivers, with an average age younger than 40 years; singles; and individuals who smoke and consume alcohol are those most likely to use psychoactive substances. In addition, among drivers who reported having consumed substances of this type, the majority, when compared to nonusers, had less time in the profession, drove for more hours during the day and traveled longer distances.

Girotto et al reported similar results in truck drivers from the port of Paranagua, concluding that those most susceptible to the use of illicit psychoactive substances were those who were younger, who had irregular working hours, who were single and who normally traveled long distances. ${ }^{15}$ Additionally, Bombana et al found that drivers who travel in the main highways in the state of São Paulo and consume illicit drugs are younger, have less experience in the profession and have a habit of driving for longer distances. ${ }^{14}$

Alcohol consumption and smoking were more prevalent among drivers who reported drug use at some point in life ${ }^{37}$. This is in line with what was previously found in the literature ${ }^{9}$. In a study carried out in Japan, alcohol appears to be associated with a younger average age, smoking, high blood pressure and a lower average $\mathrm{BMI}^{39}$.

\section{Strengths and weaknesses of the study}

This observational cross-sectional study individually estimated the effect of illicit drugs with respect to health and occupational risk factors. Our study used a large and population representative data of truck drivers that allowed a detailed analysis of the association between illicit drugs and demographic and cardiovascular risk factors. Nevertheless, due to its cross-sectional nature, the ability to elucidate causal relationships between the use of illicit drugs and health risk factors is limited. 
The scarcity of studies targeting health-related risk factors of truck drivers is a limiting factor for queries and comparisons to be made with other percentages and prevalence values found prior to this research. There is a great need to develop new research in this sector, mainly in Brazil, where the population of truck drivers is large.

Another limitation is the dependence on the reliability of the interviewees' report, who may omit information, especially with regard to drug use. On the other hand, when compared to studies based on toxicological tests, which may underestimate the use of illicit drugs because they only indicate the use of drugs in a short period prior to the examination, studies based on reports may be more comprehensive.

\section{Conclusion}

The use of illicit drugs was higher in young and single drivers and was associated with a higher prevalence of smoking, alcohol consumption and more daily driving hours, which are risk factors for NCDs, CVD and traffic accidents. Public policies to reduce drug use by these professionals can have an impact on reducing traffic accidents, as well as chronic-degenerative diseases.

\section{List Of Abbreviations}

NCDs: Chronic noncommunicable diseases

CVDs: Cardiovascular diseases

GDP: Gross domestic product

SAH: Systemic arterial hypertension

Ml: Myocardial infarction

THC: Tetrahydrocannabinol

BP: Blood Pressure

BMI: Body mass Index

BCPG: Brazilian cardiovascular prevention guidelines

\section{Declarations}

\section{Ethics approval and consent to participate}

The study was approved by the Research Ethics Committee of the School of Medicine, University of Sao Paulo (Protocol No. 2,022,550/2017) 


\section{Consent for publication}

A free and informed consent term approved by the Research Ethics Committee of the School of Medicine was applied.

\section{Availability of data and materials}

The datasets used and/or analysed during the current study are available from the corresponding author on reasonable request.

\section{Competing interests}

The authors declare that they have no competing interests.

\section{Funding}

A scholarship was granted to the author Mariana de Moura Pereira by the Coordination of Superior Level Staff Improvement (CAPES).

\section{Authors' contributions}

Mariana de Moura Pereira: conceptualised the study and was involved in all aspects of the study.

Antonio de Padua Mansur: conceptualised the study, statistical analysis and writing of this study. Júlio Yoshio Takada: statistical analysis of the data.

Vilma Leyton: conceptualised the study.

All authors contributed to refining the manuscript and approving the final draft.

\section{Acknowledgements}

This research was conducted with support from University of Sao Paulo Medical School (LIM 40/HCFMUSP) and Heart Institute (InCor) from the University of Sao Paulo Medical School. In addition, the authors wish to thank Coordination of Superior Level Staff Improvement (CAPES) for granting the financial support and to the Federal Highway Police for enabling data collection.

\section{References}

1. Confederação Nacional do Transporte - CNT. Transporte Rodoviário: Desempenho do setor, infraestrutura e investimentos. 2017.

2. Instituto de Pesquisa Econômica e Aplicada - IPEA, Polícia Rodoviária Federal - PRF. Acidentes de trânsito nas rodovias federais brasileiras. Caracterização, tendências e custos para a sociedade. 2015. 
3. Apostolopoulos Y, Sönmez S, Shattell MM, Gonzales C, Fehrenbacher C. Health survey of U.S. longhaul truck drivers: Work environment, physical health, and healthcare access. A Journal of Prevention, Assessment \& Rehabilitation. 2013;46:113-23.

4. Mansur AP, Rocha ABS, Leyton V, Takada JY, Avakian SD, Santos AJ, Novo GC, Nascimento AL, Muñoz DR, Rohlfs WJC. Risk Factors for Cardiovascular Disease, Metabolic Syndrome and Sleepiness in Truck Drivers. Arquivos Brasileiros de Cardiologia. 2015;105(6):560-5.

5. Mabry EJ, Hosig K, Hanowski R, Zedalis D, Gregg J, Herbert GW. Prevalence of metabolic syndrome in comercial truck drivers: A review. Journal of transport \& health. 2016;3:413 - 421.

6. Marcinkiewicz A, Szosland D. Selected risk factors of diabetes mellitus among road transport drivers. International Journal of Occupational Medicine and Environmental Health. 2010;23(2):175-180.

7. Instituto de Pesquisa Econômica e Aplicada - IPEA, Polícia Rodoviária Federal - PRF. Acidentes de trânsito nas rodovias federais brasileiras. Caracterização, tendências e custos para a sociedade. 2015.

8. Davey J, Richards N, Freeman J. Fatigue and Beyond: Patterns of and Motivations for illicit drug use among long-haul truck drivers. Traffic Injury Prevention. 2007;8(3):253-259.

9. Girotto E, Mesas AE, Andrade SM, Birolim MM. Psychoactive substance use by truck drivers: a systematic review. Occup Environ Med. 2014;71:71-76.

10. Yonamine M, Sanches LR, Paranhos BAPB, Almeida RM, Andreuccetti G, Leyton V. Detecting alcohol and illicit drugs in oral fluid samples collected from truck drivers in the state of São Paulo, Brazil. Traffic Injury Prevention. 2013;14(2):127-131.

11. Leyton V, Sinagawa DM, Oliveira KCBG, Schmitz W, G Andreuccetti, De Martinis BS, Yonamine M, Muñoz DR. Amphetamine, cocaine and cannabinoids use among truck drivers on the roads in the State of Sao Paulo, Brazil. Forensic science internacional. 2015;215:25 - 27.

12. Sinagawa DM, Carvalho HB, Andreuccetti G, Prado NV, Oliveira KCBG, Yonamine M, Munoz DR, Gjerde H, Leyton V. Association Between Travel Length and Drug Use among Brazilian Truck Drivers. Traffic Injury Prevention. 2015;16(1):5-9.

13. Callado LF, Morentin B. Sudden cardiac death associated to substances of abuse and psychotropic drugs consumed by young people: A population study based on forensic autopsies. Drug and Alcohol Dependence. 2019;201:23-28.

14. Bombana HS, Gjerde H, Santos MF, Jamt REG, Yonamine M, Rohlfs WJC, Muñoz DR, Leyton V. Prevalence of drugs in oral fluid from truck drivers in Brazilian highways. Forensic Science international. 2017;273:140 - 143.

15. Girotto E, Andrade SM, Mesas AE, González AD, Guidoni CM. Working conditions and illicit psychoactive substance use among truck drivers in Brazil. Occup Environ Med. 2015;72:764-769.

16. Subramaniam VN, Menezes AR, DeSchutter A, Lavie CJ. The Cardiovascular Effects of Marijuana: Are the Potential Adverse Effects Worth the High? Mo Med. 2019;116(2):146-153.

17. Kim ST, Park T. Acute and Chronic Effects of Cocaine on Cardiovascular Health. Int $\mathrm{J}$ of Mol Sci. 2019;20 no.3:584. 
18. Eman ID, Mervat MO, Eman AE, Lamia AK, Salwa AA. Marijuana use in acute coronary syndromes. The American Journal of Drug and Alcohol Abuse. 2017;43(5):576-582.

19. Serviço Social do Transporte e Serviço nacional de aprendizagem do transporte (SEST-SENAT) [Internet]. Brasil: Comandos de Saúde nas Rodovias; 2014 [cited 2018 Feb]. Available from: http://sest senates.org.br/index.php/parcerias/comandos-de-saude-nas-rodovias.

20. Johns MW. A new method for measuring daytime sleepiness: the Epworth sleepiness scale. $1991 ; 14(6): 540-545$.

21. World Health Organization. (WHO). Obesity: preventing and managing the global epidemic. Report of a WHO Consultation. 2000;Technical Report Series, n. 894.

22. Sociedade Brasileira de Cardiologia, Sociedade Brasileira de Hipertensão, Sociedade Brasileira de Nefrologia. VI Brazilian Guidelines on Hypertension. Arq Bras Cardiol. 2010;95(1 Suppl):01-51.

23. Santos RD. Sociedade Brasileira de Cardiologia. III Brazilian Guidelines on Dyslipidemias and Guideline of Atherosclerosis Prevention from Atherosclerosis Department of Sociedade Brasileira de Cardiologia. 2001;77 (Suppl 3):01-48.

24. American Diabetes Association. Diagnosis and classification of Diabetes Mellitus. Diabetes Care. 2006;29(Suppl 3):43-48.

25. Hodgdon JA, Beckett MB. Prediction of percent body fat for U.S. Navy men from body circumferences and height. Naval Health Research Center. 1984;Report No. 84-11.

26. Pinto JA, Godoy LB, Marquis VW, Sonego TB, Leal CFA, Artico MS. Anthropometric data as predictors of Obstructive Sleep Apnea Severity. Braz J Otorhinolaryngol. 2011;77(4):516-521.

27. Oliveira LG, Santos B, Gonçalves PD, Carvalho HB, Massad E, Leyton V. Attention performance among Brazilian truck drivers and its association with amphetamine use: pilot study. Revista Saúde Pública. 2013;47(5):1001-1005.

28. Takitane J, de Oliveira LG, Endo LG, Oliveira KCBG, Muñoz DR, Yonamine M, Leyton V. Uso de anfetaminas por motoristas de caminhão em rodovias do Estado de São Paulo: um risco à ocorrência de acidentes de trânsito? [Amphetamine use by truck drivers on highways of Sao Paulo State: a risk for the occurrence of traffic accidents?]. Cien Saude Colet. 2013;18:1247-54.

29. Teixeira EB. Análise da incidência do uso de anfetaminas por motoristas do litoral norte gaúcho [Trabalho de Conclusão de Curso]. Criciúma: Universidade do extremo sul catarinense; 2011. 45 p.

30. Fuchs FD, Wannmacher L, Ferreira MBCF. Farmacologia clínica:fundamentos da terapêutica racional. 3rd ed. Rio de Janeiro: Guanabara Koogan; 2004. 1074 p.

31. Agência Nacional de Vigilância Sanitária - ANVISA. Resolução- RDC Nº 52, de 6 de outubro de 2011 [Internet]; 2011 [cited 2019 Apr]. Available from:http://bvsms.saude.gov.br/bvs/saudelegis/anvisa/2011/res0052_06_10_2011.html

32. Câmara dos deputados. Legislação informatizada: Lei no 13.454, de 23 de junho de 2017 [Internet]]; 2017 [cited 2019 Apr]. Available from: https://www2.camara.leg.br/legin/fed/lei/2017/lei-13454-23junho-2017-785090-norma-pl.html 
33. Leyton V, Bombana HS, Magalhães JG, et al. Trends in the use of psychoactive substances by truck drivers in São Paulo State, Brazil: A time-series cross sectional roadside survey (2009-2016). Traffic Injury Prevention. 2019;20(2):122-127.

34. Dorta DJ, Yonamine M, Costa JL, Martinis BS. Toxicologia Forense. 1st ed. São Paulo: Blucher; 2018.

35. I Diretriz Brasileira de Prevenção Cardiovascular. Arquivos Brasileiros de Cardiologia. 2013;101.6(2).

36. Singh A, Saluja S, Kumar A, Agrawal S, Thind M, Nanda S, Shirani J. Cardiovascular Complications of Marijuana and Related Substances: A Review. Ther. 2018;7:45-59.

37. Eliveha J, Vindhyal S, Vindhyal M. Cardiac and Systemic Thrombus Caused by Drug Abuse. Case Reports in Cardiology. 2019;2019:5.

38. Shah R, Chalak B, Fan THM, Askari R, Khan MR. Cocaine-induced acute aortic dissection. The Journal of Emergency Medicine. 2015; 49(3):87- 89.

39. Sakurai S, Cui R, Tanigawa T, Yamagishi K, Isso H. Alcohol consumption before sleep is associated with severity of sleep-disordered breathing among professional Japanese truck drivers. Alcohol Clin Exp Res. 2007;31:2053-8.

\section{Figures}

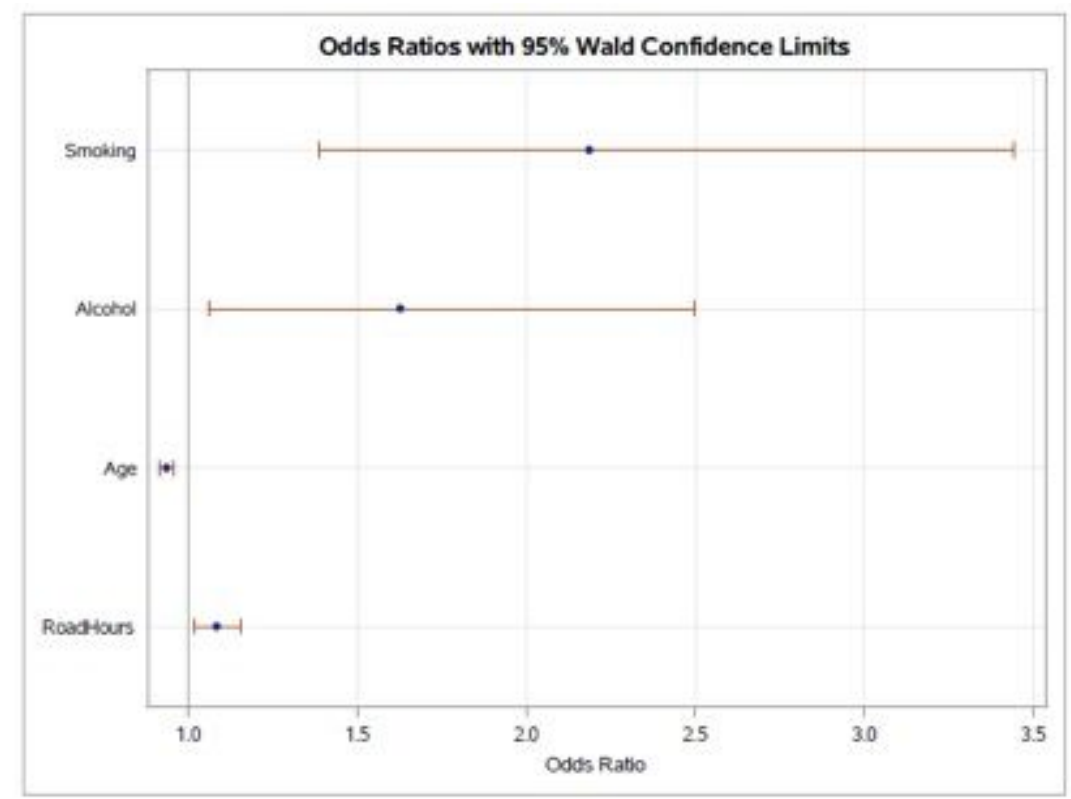

\section{Figure 1}

Odds ratio chart for the independent variables smoking, alcohol consumption, age and hours of driving per day in the logistic regression analysis for the dependent variable illicit drugs. 